\title{
Accuracy and precision of hatchling sea-finding orientation relative to dune proximity in three species of sea turtles
}

\section{Shigetomo Hirama ( $\sim$ Tomo.Hirama@myfwc.com )}

Florida Fish and Wildlife Conservation Commission https://orcid.org/0000-0002-6189-2976

\section{Blair Witherington}

Inwater Research Group, Inc.

\section{Sarah Hirsch}

Loggerhead Marinelife Center

\section{Erin Leone}

Florida Fish and Wildlife Conservation Commission

Raymond Carthy

USGS: US Geological Survey

\section{Research Article}

Keywords: Sea turtle hatchlings, sea-finding orientation, dune proximity

Posted Date: March 25th, 2021

DOl: https://doi.org/10.21203/rs.3.rs-283808/v1

License: (c) (1) This work is licensed under a Creative Commons Attribution 4.0 International License. Read Full License 


\section{Abstract}

Sea turtle hatchlings emerge from nests at night on sand beaches and immediately orient using visual cues. These cues involve horizon brightness, and on beaches without artificial lighting, hatchling orientation is seaward. Although many studies have examined which visual cues influence hatchling orientation, we found no work focused on a comparison of orientation among species. The purpose of the present study was to understand how dune proximity (distance from nest to dune silhouette) comparatively affected hatchling orientation in three sea turtle species sharing the same nesting beach. We measured accuracy and precision of hatchling orientation in hatchling loggerheads (Caretta caretta), green turtles (Chelonia mydas), and leatherbacks (Dermochelys coriacea), using tracks left in beach sand. Generalized linear models were used to test for effects from nest-dune distance in each species. We found that green turtle hatchlings had better orientation than loggerhead hatchlings. The results also showed that there was a significant decrease in hatchling orientation accuracy and precision in all species as the distance between nests and dune increased. We conclude that dune features are likely to provide important cues for hatchling orientation on sea turtle nesting beaches. Considering the importance of beach dunes to sea-finding success of hatchlings, we recommend management strategies to maintain natural beach profiles on sea turtle nesting beaches.

\section{Introduction}

Sea turtles lay eggs in nests on sand beaches. Hatchlings emerge from their nests at night (Mrosovsky 1968) after an incubation period about 45-80 days (Miller 1997). Immediately after emerging, hatchlings crawl vigorously in an attempt enter the sea along a direct path. Crawling along an indirect path would be an inefficient use of limited energy and risk exhaustion and dehydration (Lorne and Salmon 2007) and predation mortality (Tomillo et al. 2010). Among multiple possibilities for orientation cues that would guide accurate and precise seaward orientation, visual cues have the greatest support from experimental evidence (Mrosovsky and Shettleworth 1968; Tuxbury and Salmon 2005). For example, loggerhead hatchlings crawled in the opposite direction of artificially created dark silhouettes in both laboratory and in situ experiments (Parker 1922; Salmon et al. 1992; Tuxbury and Salmon 2005).

Since the first publication of sea turtle hatchling orientation studies in 1908 (Hooker), work has been conducted on all sea turtle species, yet there are no location-controlled, species comparative studies. Understanding the relative orientation performance of hatchlings by species is important for assessing needs for and effects from nesting beach management. The purpose of the present study was to assess hatchling orientation in three sea turtle species sharing the same nesting beach and to evaluate the relationship between their orientation and the distance from nest to the dune. We hypothesized that if the three species of sea turtles perceive light similarly, then we would measure greater orientation accuracy and precision in green turtles (Chelonia mydas), compared to loggerheads (Caretta caretta) and leatherbacks (Dermochelys coriacea), because green turtles tend to nest higher on the beach and closer to the dune (Witherington 1986; Wetterer et al. 2007). 


\section{Methods}

\section{Study sites and hatchling orientation parameters}

Our study location was the sea turtle nesting beach at Juno Beach (hereafter Juno), Florida (from $26.392^{\circ} \mathrm{N}, 80.067^{\circ} \mathrm{W}$ to $26.970^{\circ} \mathrm{N}, 80.080^{\circ} \mathrm{W}$ ), one of few beaches in the world where three sea turtle species nest in significant numbers. We conducted early morning surveys at Juno during the summer hatchling emergence season between 2015 and 2018 to collect orientation data from hatchling tracks resulting from emergences occurring the previous night. Data came from 180 loggerhead, 56 green turtle, and 15 leatherback hatchling emergence events. We measured two parameters to represent hatchling orientation: 1) an angular range that shows the spread of hatchling tracks and indicates precision of orientation, and 2) a modal divergence that shows the difference between the most frequent direction hatchlings crawled and the ocean direction, used to quantify orientation accuracy (Salmon and Witherington 1995; Berry et al. 2013; Kamrowski et al. 2014; Dimitriadis et al. 2018, Hirama et al. in review).

Hatchling track orientation was measured at a subsample of nests marked for nest productivity assessments (Brost et al. 2015). These productivity assessments took place for every $20^{\text {th }}$ nest location for loggerheads and all green turtle and leatherback nests. At these nests, surveyors searched the beach for hatchling tracks and used a compass in a phone app to measure angular range and modal divergence using the nest (track origin) as the measuring point. We could collect data only from a subsample of the marked nests because some were unsuccessful. We ignored nests with fewer than five hatchling tracks (Pendoley 2005; Berry et al. 2013; Kamrowski et al. 2014; Hirama et al. in review) or that had tracks erased by wind or human footprints. The distance between an emergence point and the vegetation line, which is often described as the toe of dune, was measured using a laser range finder (Laser Technology: TruPulse 200). The data were collected throughout the study area and hatchling emergence season without bias in data collection efforts; therefore, we consider abiotic effects, such as sand color, moon illumination percentage, cloud cover percentage, dune height, dune vegetation density, slope steepness, ocean tide, etc., to be random factors.

\section{Statistical Analyses}

We created generalized linear mixed models (GLMM) with angular ranges and modal divergences as response variables and with species and distance to dune (and their interaction) as the explanatory variables using SAS v 9.4 (Cary, NC). Because of the highly skewed and discrete (integer) nature of the data (Fig. 1A, B), we assumed a negative binomial distribution. Because data were collected over multiple years, we included year as a random factor to allow for correlation between nests within a given year. To understand orientation accuracy and precision differences among species (data with linear distributions), we used Dunn's post-hoc tests for pair-wise multiple comparisons, using program $\mathrm{R}$ with the FSA package (Ogle et al. 2018). 


\section{Results}

We collected the two hatchling orientation parameters from 251 nests across three species (Table 1). Angular ranges were significantly different among species $\left(\mathrm{F}_{2,179}=3.09, P=0.0478\right)$. The values of this parameter significantly increased in all species with increased distance to dune $\left(F_{1,179}=35.61, P<0.001\right.$, Fig. 2A, Table 1). We also found significant differences among species in the modal divergence parameter $\left(\mathrm{F}_{2,179}=3.64, P=0.0282\right)$, with precision decreasing as distance to dune increased $\left(\mathrm{F}_{1,179}=\right.$ 15.39, $P<0.001$, Fig. 2B, Table 1). We rejected our null hypothesis stating that green turtles, loggerheads, and leatherbacks would have the same hatchling orientation precision and accuracy. The results of posthoc pair-wise comparison tests showed green turtles nested significantly closer to the dune than the loggerheads $(Z=-8.36, P=<0.001)$ and leatherbacks $(Z=-3.61, P=<0.001)$, with no difference between the latter two species, $Z=-8.56, P=0.39$ (Fig. 3). Green turtles had a significantly smaller angular range $(Z=-3.15, P=0.002)$ and modal divergence $(Z=-3.28$, $p$-value $=0.001)$ than loggerheads (Fig. 2A). However, comparisons of green turtles and leatherbacks (angular range: $Z=-0.26, P=0.79$, modal divergence: $Z=-1.55, P=0.12$ ) and leatherbacks and loggerheads (angular range: $Z=-1.51, P=$ 0.13 , modal divergence: $Z=-0.20, P=0.84$ ) showed orientation parameters that were not significantly different (Fig. 2B).

Table 1 Descriptive statistics of two parameters (angular range and modal divergence) that describe the precision and accuracy of hatchling orientation at Juno Beach, Florida, USA.

\begin{tabular}{ccccccc}
\hline Species & Sample size & Parameter & Mean & SD & Median & Range \\
\hline Green turtle & 56 & Angular range & $42^{\circ}$ & $\pm 18^{\circ}$ & $40^{\circ}$ & $13-113^{\circ}$ \\
Loggerhead & 180 & Angular range & $69^{\circ}$ & $\pm 57^{\circ}$ & $49^{\circ}$ & $6-360^{\circ}$ \\
\hline Leatherback & 15 & Angular range & $50^{\circ}$ & $\pm 34^{\circ}$ & $39^{\circ}$ & $7-133^{\circ}$ \\
\hline Green turtle & 56 & Modal divergence & $7^{\circ}$ & $\pm 14^{\circ}$ & $4^{\circ}$ & $0-106^{\circ}$ \\
\hline Loggerhead & 180 & Modal divergence & $14^{\circ}$ & $\pm 21^{\circ}$ & $7^{\circ}$ & $0-126^{\circ}$ \\
\hline Leatherback & 15 & Modal divergence & $8^{\circ}$ & $\pm 7^{\circ}$ & $7^{\circ}$ & $1-28^{\circ}$ \\
\hline
\end{tabular}

\section{Discussion}

Given that the orientation accuracy and precision of loggerheads, green turtles, and leatherbacks increased similarly with nest proximity to the dune and given the sensitivity of hatchlings to horizon brightness, we hypothesize that a dark dune silhouette is equally important to correct orientation across the three species. The importance of dunes in loggerhead hatchling orientation has been confirmed in previous studies (Parker 1922; Salmon et al. 1992; Tuxbury and Salmon 2005; Hirama et al. in review), but evidence concerning green turtles and leatherbacks is lacking. 
Because green turtles place their nests closer to the dune than do loggerheads and leatherbacks, it is possible that green turtle hatchlings are more likely to perceive strong initial light cues from the dune silhouette, which contrasts with the brighter, open, seaward horizon. In the present study, leatherback and loggerhead nest placement (distance between nest and dune) was similar and differed from green turtle nest placement. Although we predicted that leatherback orientation accuracy and precision would be significantly lower than in green turtles, leatherback hatchlings showed the same orientation accuracy and precision as green turtles. However, we note that our sample size for leatherback nests was small ( $n$ $=15$ nests) compared to green turtle nests ( $n=56$ nests), which may have provided insufficient statistical power to discern differences. Both within and between species, hatchling orientation was better in nests that were closer to the dune. These results do not resolve the hierarchy of cues from silhouette patterns and brightness (Limpus 1971; Van Rhijn 1979), however, our results do support the hypothesis that form or brightness characteristics of the dune have an important influence on hatchling orientation.

We conclude that the dune, which on sea turtle nesting beaches provides a dark silhouette contrasting with seaward, is an important environmental factor for hatchling orientation, thus confirming assessments by other authors (Parker 1922; Salmon et al. 1992). Because the height of the dune throughout the beach at Juno was relatively uniform, we consider this to be a minimally important random factor. The applicability of our results to hatchling orientation on other beaches may depend on important variables such as the amount of artificial lighting and how artificial light fields are affected by dunes. We hypothesize that on naturally lighted beaches with minimal artificial light, there would be similar effects from dune proximity on orientation. In other work we have done on hatchling orientation relative to environmental factors, we found distance between nest and dune to be the most influential among several factors (Hirama et al. in review).

The findings of the current study suggest that the same beach management strategies-- protecting coastal pioneer plants such as sea oats, sea grape, and saw palmettos that promote dune formation and block ambient light--might be implemented ubiquitously because of the importance of the dune as a guiding feature across sea turtle species.

Acknowledgments We thank D. Aoki, K. Ariotti, S. Bolds, W. Brown, B. Canitz, G. Carvajal, S. Colios, A. Ferrera, K. Fraser, A. Frye, R. Grimley, S. Hoover, R. Johnson, K. Kantra, S. Kedzuf, E. Kelly, E. Kluga, A. McCracken, M. O'Briant, J. Reilly, K. Rigano, H. Seaman, J. Stuczynski, L. Wenk, and M. Wilgus for the field assistance. We thank K. Bjorndal, S. Johnson, and E. Lada for providing technical guidance. We thank S. A. Ceriani, B. Crowder, and A. M. Foley for reviewing the manuscript. This study was performed under the authorization of the Florida Fish and Wildlife Conservation Commission Marine Turtle Permit, MTP-154. Any use of trade, firm, or product names is for descriptive purposes only and does not imply endorsement by the U.S. Government.

\section{Declarations}

Ethical approval The study does not contain any experiment using animals by any of the authors. 
Conflict of interest The authors declare that they have no conflict of interest.

\section{References}

1. Berry M, Booth DT, Limpus CJ (2013) Artificial lighting and disrupted sea-finding behaviour in hatchling loggerhead turtles (Caretta caretta) on the Woongarra coast, south-east Queensland, Australia. Aust J Zool 61:137-145

2. Brost B, Witherington B, Meylan A, Leone E, Ehrhart L, Bagley D (2015) Sea turtle hatchling production from Florida (USA) beaches, 2002-2012, with recommendations for analyzing hatching success. Endanger Species Res 27:53-68. doi 10.3354/esr00653

3. Dimitriadis C, Fournari-Konstantinidou I, Sourbes L, Koutsoubas D, Mazaris AD (2018) Reduction of sea turtle population recruitment caused by nightlight: evidence from the Mediterranean region. Ocean Coast Manage 153:108-115

4. Hirama S, Witherington B, Kneifl K, Sylvia A, Wideroff M, Carthy R (in review) Environmental factors predicting the orientation of sea turtle hatchlings on a natural beach: a baseline for lightmanagement goals. J Exp Mar Biol Ecol, in review

5. Hooker D (1908) The breeding habits of the loggerhead turtle and some early instincts of the young. Science 27:490-491

6. Kamrowski RL, Limpus C, Pendoley K, Hamann M (2014) Influence of industrial light pollution on the sea-finding behaviour of flatback turtle hatchlings. Wildlife Res 41:421-434. doi:10.1071/wr14155

7. Lorne JK, Salmon M (2007) Effects of exposure to artificial lighting on orientation of hatchling sea turtle on the beach and in the ocean. Endanger Species Res 3:23-30. doi:10.3354/esr003023

8. Miller JD (1997) Reproduction in sea turtles. In: Lutz PL, Musick JA (eds) The Biology of Sea Turtles. CRC Press, Boca Raton, pp 51-81

9. Mrosovsky N (1968) Nocturnal emergence of hatchling sea turtles: control by thermal inhibition of activity. Nature 220:1338-1339

10. Mrosovsky N, Shettleworth SJ (1968) Wavelength preferences and brightness cues in water finding behaviour of sea turtles. Behaviour 32:211-257

11. Ogle D, Wheeler P, Dinno A (2018) Simple Fisheries Stock Assessment Methods. R package Version 0.8.22. https://cran.r-project.org/web/packages/FSA/FSA.pdf (accessed 20 April 2018)

12. Parker GH (1922) The crawling of young loggerhead turtles toward the sea. J Exp Zool 3:322-331

13. Pendoley KL (2005) Sea turtles and the environmental management of industrial activities in north west Western Australia. Ph.D. Thesis, Murdoch University, Perth

14. Salmon M, Witherington BE (1995) Artificial lighting and seafinding by loggerhead hatchlings: Evidence for lunar modulation. Copeia 1995:931-938. doi:10.2307/1447042

15. Salmon M, Wyneken J, Fritz E, Lucas M (1992) Seafinding by hatchling sea turtles role of brightness, silhouette and beach slope as orientation cues. Behaviour 122:56-77.

doi:10.1163/156853992x00309 
16. Tomillo PS, Paladino FV, Suss JS, Spotila JR (2010) Predation of leatherback turtle hatchlings during the crawl to the water. Chelonian Conserv Biol 9:18-25. doi 10.2744/ccb-0789.1

17. Tuxbury SM, Salmon M (2005) Competitive interactions between artificial lighting and natural cues during seafinding by hatchling marine turtles. Biol Conserv 121:311-316.

doi:10.1016/j.biocon.2004.04.022

18. Van Rhijn FA (1979) Optic orientation in hatchlings of the sea turtle, Chelonia mydas I. Brightness: Not the only optic cue in sea-finding orientation. Mar Freshw Behav Phy 6:105-121

19. Wetterer JK, Wood LD, Johnson C, Krahe H, Fitchett S (2007) Predaceous ants, beach replenishment, and nest placement by sea turtles. Environ Entomol 36:1084-1091

20. Witherington BE (1992) Behavioral responses of nesting sea-turtles to artificial lighting. Herpetologica 48:31-39

21. Witherington BE (1986) Human and natural causes of marine turtle clutch and hatchling mortality and their relationship to hatchling production on an important Florida nesting beach. M.S. thesis, University of Central Florida, Orlando; 1986, 141 pp

\section{Figures}
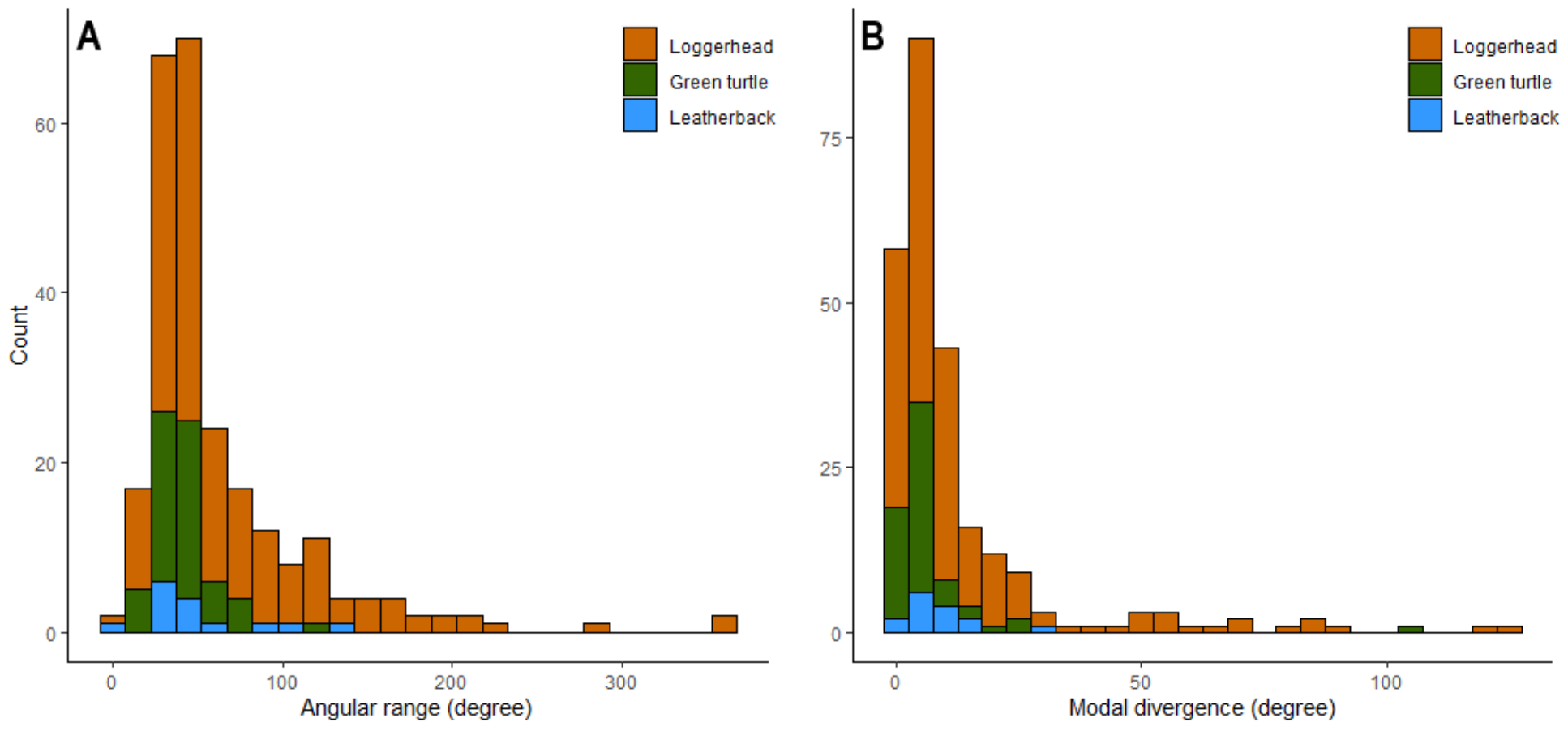

Figure 1

Distribution of angular range and modal divergence that describes three species of sea turtle hatchling. 

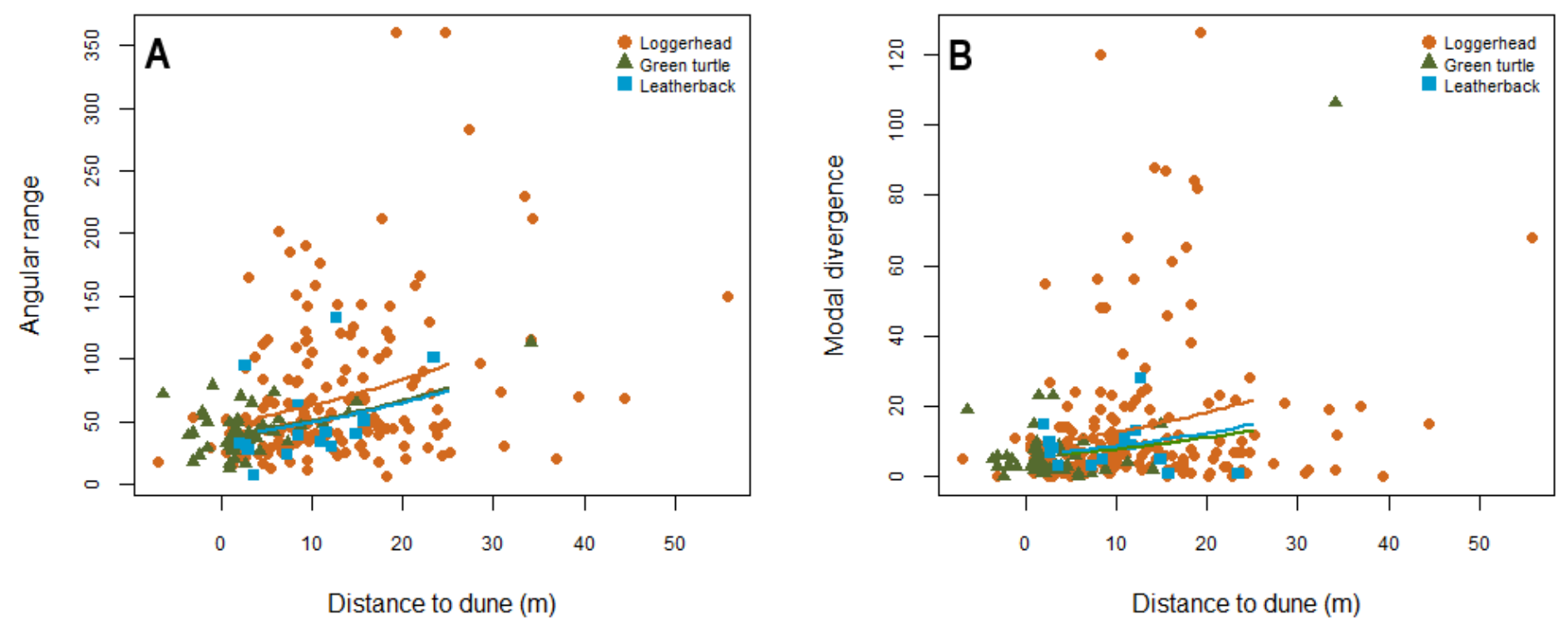

Figure 2

The relationship between hatchling (A) orientation precision and (B) accuracy (expressed as angular range and modal divergence, respectively) and distance from a nest to dune are plotted for three species of sea turtles. 


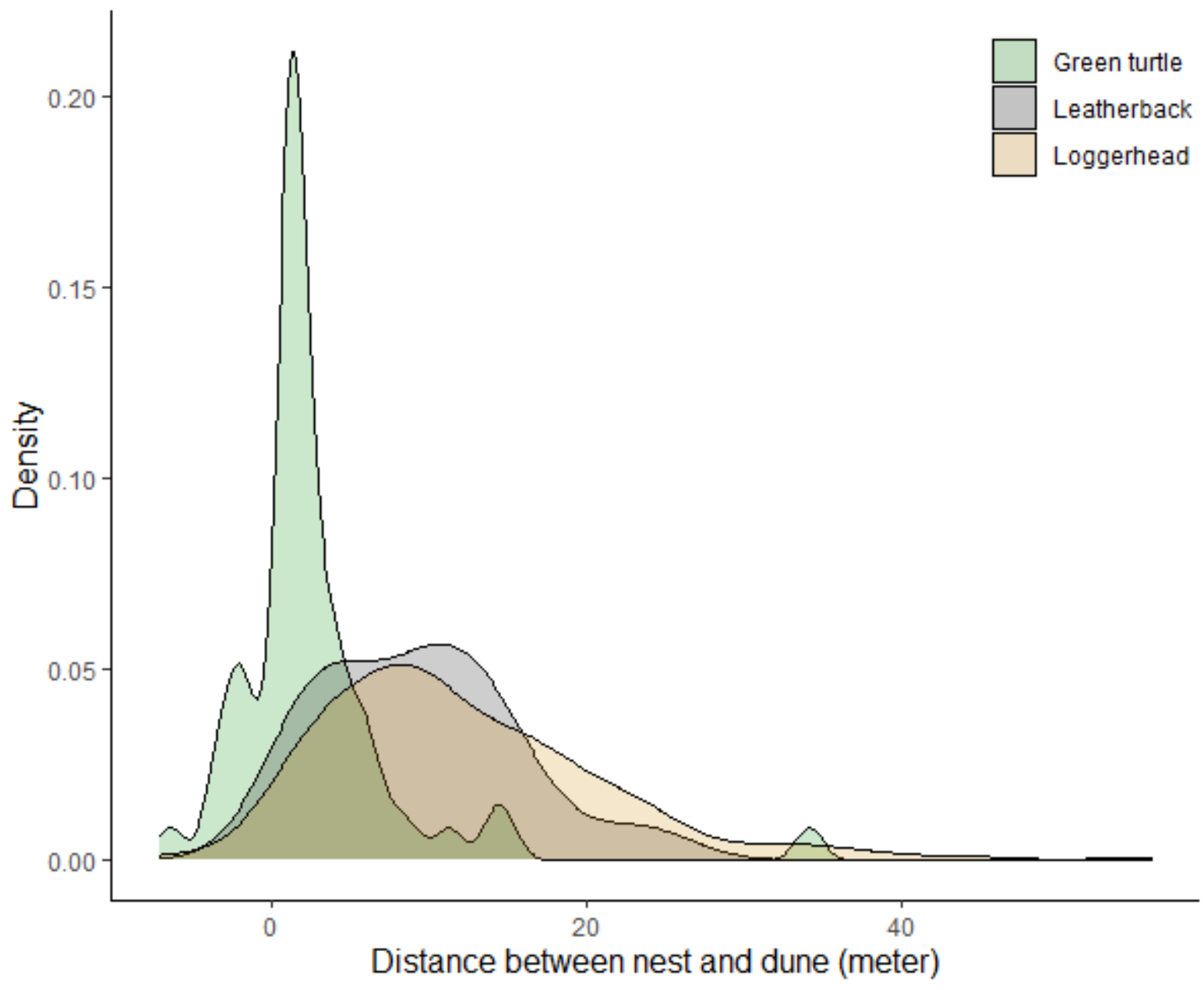

Figure 3

Density of sea turtle nest locations in relation to distance between nests and dune (value 0 on the x-axis shows the vegetation line (that is roughly equal to toe of dune) by species. Loggerhead (mean $=12.2 \mathrm{~m}$, median $=9.9 \mathrm{~m}$, range $=\nabla 7.0-55.8 \mathrm{~m}, \mathrm{SD}=9.2 \mathrm{~m})$, green turtle $($ mean $=2.8 \mathrm{~m}$, median $=1.5 \mathrm{~m}$, range $=$ $\otimes 6.4-34.1 \mathrm{~m}, \mathrm{SD}=5.7 \mathrm{~m}$ ), and leatherback (mean $=8.5 \mathrm{~m}$, median $=9.4 \mathrm{~m}$, range $=2.1-23.5 \mathrm{~m}, \mathrm{SD}=$ $6.1 \mathrm{~m})$. 